\title{
KONSTRUKSI INFINITIF DALAM BAHASA JERMAN
}

\author{
oleh Pratomo Widodo \\ FBS Universitas Negeri Yogyakarta
}

\begin{abstract}
In German syntactic structure, an infinitive verb combines with a finite verb in a verb phrase or complex verb to perform its function as the predicate of a sentence. A syntactic construction which includes an infinitive form is called an infinitive construction.

Infinitive constructions in German are of two types: coherent and incoherent ones. The first type has no syntactic value and can function only as the predicate of a sentence but the second type has a syntactic value and is a form of quasi-sub-clause. Both types are found in some syntactic constructions.
\end{abstract}

Keywords: infinitive, coherent, incoherent

\section{A. PENDAHULUAN}

Dalam kalimat bahasa Jerman fungsi predikat selalu dijalankan oleh verba, baik dalam tataran kata maupun frasa. Predikat yang berupa kata, yang juga disebut sebagai verba sederhana (Einfaches Verb), mengemban dua fungsi, yaitu secara morfosintaksis sebagai verba finit, yang ditandai oleh konjugasi verba; dan sekaligus sebagai verba utama dengan makna leksikal penuh. Sementara itu, predikat yang berupa frasa terdiri dari dua bagian yaitu verba finit (yang dikonjugasikan) dengan makna gramatikal sebagai verba bantu; dan verba infinit yang berperan sebagai verba utama dengan makna leksikal sebagai inti predikat. Dalam bahasa Jerman frasa verbal disebut juga sebagai verba kompleks (Verbalkomplex). Terdapat dua jenis verba infinit dalam konstruksi verba kompleks bahasa Jerman, yaitu verba bentuk partisipel dan verba bentuk infinitif.

Bentuk infinitif adalah bentuk dasar yang tidak dikonjugasikan. Bentuk infinitif dalam verba kompleks bahasa Jerman penggunaanya dibedakan menjadi dua, yaitu infinitif dan infinitif dengan $z u$ ( $z u$ infinitif), seperti terlihat pada contoh kalimat (1) dan (1a) berikut.
(1) Ilona will ihre Mutter besuchen.

'Ilona akan mengunjungi ibunya.'

(1a) Ilona glaubt, ihre Mutter zu besuchen.

'Ilona berpikir, untuk mengunjungi ibunya.'

Pemakaian bentuk infinitif dalam bahasa Jerman tergolong produktif dan memiliki bentuk konstruksi dan makna yang berbeda-beda. Oleh sebab itu, konstruksi yang mengandung unsur infinitif ini seringkali dirasakan membingungkan oleh pembelajar Indonesia yang belajar bahasa Jerman. Tulisan ini akan mendeskripsikan konstruksi infinitif dalam kalimat bahasa Jerman dan mencoba memberikan masukan sebagai alternatif dalam pengajaran bahasa Jerman, khususnya bagi pembelajar Indonesia.

\section{B. VERBAL KOMPLEKS}

Sebelum sampai pada konstruksi infintif, terlebih dahulu disampaikan verbal kompleks dalam bahasa Jerman. Verbal kompleks dengan unsur infinitif terdiri dari verba finit dan bentuk infinitif. Letak dari kedua verba tersebut dalam kalimat tergantung dari tipe kalimat berdasarkan pendekatan topologis, yaitu berdasarkan rangka kalimat (Satzrahmen) 
dengan melihat letak verba dan nomina, serta unsur lain dalam kalimat. Berdasarkan pendekatan tersebut dapat digambarkan skema topologis kalimat bahasa Jerman seperti berikut (diadaptasi dari DUDEN, 2005).

Pada skema induk kalimat di atas tampak bahwa verbal kompleks merupakan konstruksi diskontinu dengan verba finit berada pada posisi kedua sebagai rangka kalimat kiri
(Linke Satzrahmen/ $L S$ ) dan verba infinitif berada pada posisi terakhir sebagai rangka kalimat kanan (Rechte Satzrahmen/ RS), sehingga kedua unsur verbal tersebut membentuk suatu kerangka verbal (Verbalrahmen). Jenis kalimat yang termasuk pada tipe ini adalah kalimat induk indikatif dan kalimat tanya dengan elemen tanya. Berikut disampaikan contohnya.

Induk Kalimat (Hauptsatz):

\begin{tabular}{|c|c|c|c|}
\hline Vorfeld & LS & Mittelfeld & $R S$ \\
\hline & verba finit & & verba infinitif \\
\hline
\end{tabular}

Anak Kalimat (Nebensatz):

\begin{tabular}{|c|c|c|c|}
\hline LS & Mittelfeld & \multicolumn{2}{|c|}{$R S$} \\
\hline Subjungsi & & v. infinitif & v. finit \\
\hline
\end{tabular}

Keterangan:

Vorfeld: Bidang Depan

Mittelfeld: Bidang Tengah

LS (Linke Satzrahmen): Rangka Kalimat Kiri

RS (Rechte Satzrahmen): Rangka Kalimat Kanan

(2) Anna will seinen Freund am Bahnhof abholen.

'Anna akan menjemput pacarnya di stasiun.'

(2a) Wen will Anna am Bahnhof abholen?

'Anna akan menjemput siapa di satasiun?'

Kalimat tanya yang berunsurkan ifinitif dengan alternatif jawaban $j a$ ' $\mathrm{ja}$ ' atau nein 'tidak' ( $\mathrm{Ja} /$ nein Frage atau Entscheidungsfrage) juga merupakan konstruksi diskontinu. Pada jenis kalimat tanya ini tidak terdapat bidang depan (Vorfeld), karena kalimat diawali oleh verba finit yang sebagai rangka kalimat kiri (Linke Satzrahmen) dan diakhiri oleh verba infinitif sebagai rangka kalimat kanan (Rechte Satzrahmen). Contoh:

(3) Will Anna seinen Freund am Bahnhof abholen?

'Akan(kah) Anna menjemput pacarnya di stasiun?'

Pada skema anak kalimat tampak bahwa kalimat diawali dengan subjungsi atau konjungsi subordinatif sebagai rangka kalimat kiri dan diakhiri dengan verba kompleks sebagai rangka kalimat kanan dengan urutan verba infinitif-finit. Di antara rangka kalimat kiri dan kanan, atau pada bidang tengah (Mittelfeld), terdapat unsur-unsur kalimat selebihnya. Berikut disampaikan contohnya.

(4) Anna sagt, dass sie seinen Freund am Bahnhof abholen will.

'Anna bilang, bahwa ia akan menjemput pacarnya di stasiun.'

\section{KONSTRUKSI INFINITIF}

Menurut Glück (1993) yang dimaksud dengan infinitif adalah verba bentuk dasar atau verba sebutan yang tidak dikonjugasikan, oleh karena itu verba infinitif tidak memiliki informasi yang berkaitan dengan persona, kala, jumlah, dan modus. Secara morfologis bentuk infinitif dalam bahasa Jerman ditandai dengan sufiks - en atau - $n$, seperti pada verba kaufen 'membeli' dan sammeln 'mengumpulkan'. 
Bentuk infinitif digunakan antara lain dalam konstruksi infinitif. Adapun yang dimaksud dengan konstruksi infinitif adalah konstruksi sintaksis yang mengandung unsur infinitif (Glück, 1993; Eisenberg, 1994). Karena bentuk infinitif tidak dikonjugasikan maka penggunaannya dalam kalimat selalu berdampingan dengan verba finit (yang dikonjugasikan) dalam bentuk verba kompleks. Ditinjau dari hubungan antara verba finit dan verba infinitif dalam kalimat, konstruksi infintif dikelompokkan menjadi dua, yaitu konstruksi infinitif koheren dan konstruksi infinitif inkoheren (Glück, 1993; Eisenberg 1994; DUDEN, 2005).

Konstruksi infinitif disebut koheren bila antara unsur infinitif dan verba finit terdapat hubungan dependensi, di mana secara struktural unsur infinitif merupakan bagian subordinat dari verba finit. Kedua unsur tersebut, verba finit dan infinitif, membentuk sebuah verba kompleks (Verbalkomplex) yang berfungsi sebagai predikat kalimat. Oleh sebab itu, unsur infinitif bukan merupakan verba yang mandiri, sehingga unsur infinitif tidak bernilai sintaksis (nicht satzwertig). Berikut disampaikan contoh penjelasnya.

(5) Das will ich mir noch einmal überlegen.

'Saya akan mempertimbangkannya sekali lagi.'

Pada contoh (5) di atas terlihat bahwa bentuk infinitif überlegen 'mempertimbangkan' bersama-sama dengan verba modal will 'akan', yang berperan sebagai verba finit, menjalankan fungsi predikat kalimat (5) yang bersubjek ich 'saya'. Apabila predikat kalimat diubah menjadi verba sederhana (Einfaches Verb) maka verba überlegen akan menduduki posisi sebagai verba finit, sehingga bentuknya menjadi überlege. Perubahan bentuk predikat dari verba kompleks menjadi verba sederhana tersebut akan menghasilkan kalimat seperti contoh (5a) berikut.

(5a) Das überlege ich mir noch einmal.

'Saya mempertimbangkannya sekali lagi.'

Dengan membandingkan kedua contoh kalimat di atas (5 dan 5a) terlihat bahwa yang menjadi verba utama dengan makna leksikal penuh adalah verba überlegen. Pada kalimat (5) verba tersebut bersama-sama dengan verba finit will membentuk predikat kalimat. Oleh sebab itu konstruksi infinitif pada kalimat (5) bersifat koheren, karena di antara verba finit will dan verba infinitif überlegen terdapat hubungan dependensi.

Konstruksi infinitif diklasifikasikan sebagai inkoheren bila antara verba infinitif dan verba finit tidak terdapat hubungan dependensi. Berbeda dengan konstruksi infinitif koheren, pada konstruksi infinitif inkoheren unsur infinitif tidak tergantung pada verba finit, namun menjalankan fungsi predikasi secara mandiri dalam suatu frasa. Frasa itu dinamakan sebagai frasa infinitif, karena yang menjadi inti frasanya adalah verba infinitif. Frasa infintif yang demikian memiliki perilaku sintaksis yang mirip atau dekat dengan konstruksi anak kalimat, yang dalam bahasa Jerman disebut Nebensatz. Oleh sebab itu, konstruksi infinitif yang inkoheren memiliki nilai anak kalimat atau nebensatzwertig yang kemudian secara lebih singkat disebut sebagai bernilai kalimat atau satzwertig (DUDEN, 2005).

Karena konstruksi (frasa) infintif inkoheren memiliki perilaku yang mirip dengan anak kalimat (Nebensatz) dan oleh karenanya bernilai anak kalimat (nebensatzwertig), maka konstruksi tersebut kebanyakan terdapat pada kuasi kalimat majemuk bertingkat. Yang dimaksud dengan kuasi kalimat majemuk bertingkat di sini, adalah kalimat majemuk yang anak kalimatnya tidak memiliki unsur yang lengkap karena tidak adanya subjek. Sebetulnya subjek tersebut ada namun tidak muncul secara eksplisit. Subjek pada konstruksi infinitif merujuk pada unsur yang ada pada induk kalimat, dan unsur yang dimaksud dapat berupa subjek, objek, maupun korelat. Karena ketiadaan subjek formal pada konstruksi infinitif inkoheren, dan oleh karenanya tidak ada yang dapat dirujuk oleh verba melalui peristiwa konjugasi yang menghasilkan verba finit, maka digunakan verba bentuk $z u+$ infinitif (infinitif dengan $z u$ ). Bentuk $z u+$ 
infinitif itu tidak berhubungan dengan verba finit (pada induk kalimat), melainkan menjalankan fungsi predikat "anak kalimat" yang berupa frasa infinitif dalam konstruksi infinitif yang inkoheren. Berikut disampaikan contoh penjelasnya.

(6) Der Arzt empfahl mir, mehr Obstzu essen.

'Dokter menyarankan saya, untuk makan lebih banyak buah-buahan.'

Pada dasarnya contoh (6) di atas merupakan kuasi kalimat majemuk bertingkat. Kalimat pertama atau "induk" ditandai dengan verba empfahl 'menyarankan' dan subjeknya adalah der Arzt 'dokter'. Kalimat kedua atau "anak kalimat" ditandai dengan verba zu essen 'makan' dan subjeknya adalah objek pada kalimat pertama atau "induk" mir 'saya', sementara Obst 'buah-buahan' adalah objeknya. Konstruksi infinitif pada kalimat (6) di atas bersifat inkoheren, karena verba infinitif $z u$ essen 'makan' tidak memiliki hubungan dependensi (semantik) dengan verba finit empfahl 'menyarankan', melainkan menjalankan fungsi predikatnya sendiri. Oleh karena itu, konstruksi infinitif pada kalimat (6) bernilai kalimat (satzwertig) atau lebih tepatnya bernilai anak kalimat (nebensatzwertig).

Apabila kalimat (6) diparafrasekan menjadi kalimat majemuk dengan unsur-unsur yang lengkap, maka akan diperoleh kalimat (6a) berikut.

(6a) Der Arzt empfahl mir, daâ ich mehr Obst essen soll.

'Dokter menyarankan saya, agar saya makan lebih banyak buah-buahan.'

Kalimat (6a) adalah kalimat majemuk bertingkat yang semua unsurnya lengkap, baik pada induk kalimat maupun anak kalimat. Kedua kalimat tersebut memiliki subjeknya masing-masing, yaitu der Arzt 'dokter' pada induk kalimat, dan ich 'saya' pada anak kalimat. Objek pada induk kalimat mir 'saya' yang berkasus datif itu muncul sebagai subjek pada anak kalimat dengan kasus nominatif ich 'saya'. Karena kalimat (6a) merupakan kalimat majemuk yang semua unsurnya lengkap, maka di sana tidak terdapat konstruksi infinitif yang inkoheren. Infinitif essen 'makan' pada contoh (6a) bersifat koheren karena memiliki hubungan dependensi dengan verba finit modal soll (sollen) 'agar' dan kedua verba tersebut (essen dan soll) secara bersama-sama menjalankan fungsi predikat anak kalimat. Dalam bahasa Jerman konstruksi verba modal sollen + infinitif seperti pada contoh (6a) di atas (essen soll) digunakan untuk mengungkapkan perintah atau himbauan tidak langsung yang berasal dari orang ketiga. Berdasarkan perbandingan dari kedua contoh di atas (6 dan 6a), diketahui bahwa bentuk infinitif zu essen pada contoh (6) dan essen pada contoh (6a) memiliki fungsi yang berbeda.

Selanjutnya disampaikan uraian tentang konstruksi sintaksis yang mengandung konstruksi infinitif baik yang koheren maupun yang inkoheren.

\section{Konstruksi Infinitif Koheren}

Seperti telah diuraikan di atas, bahwa pada konstruksi infinitif koheren unsur infinitif memiliki hubungan dependensi dengan verba finit dan secara bersama-sama kedua unsur verbal tersebut membentuk predikat kalimat dalam bentuk verba kompleks (Verbalkomplex). Oleh karena itu, konstruksi infinitif koheren terdapat pada konstruksi kalimat yang predikatnya berupa verba kompleks. Verba kompleks yang mengandung unsur infintif koheren terdapat pada konstruksi kala Futur I, Modal, Kuasi Modal, Modalitas, dan Modalitas Pasif. Berikut disampaikan penjelasannya masing-masing.

\section{a. Futur I}

Konstruksi kala Futur I terdiri dari verba bantu futur werden dan verba bentuk infinitif. Dalam bJ konstruksi Futur I memiliki dua makna, yaitu (1) sebagai kala mendatang, dan (2) sebagai modalitas pengungkap suatu dugaan pada peristiwa yang (mungkin) sedang terjadi. Sebagai kala mendatang, kalimat dengan konstruksi verbal Futur I mengindikasikan suatu kegiatan yang akan berlangsung pada masa yang akan datang, namun demikian tidak merujuk pada suatu titik 
waktu tertentu. Untuk merujuk pada waktu yang tertentu masih perlu ditambahkan adverbia temporal. Contoh:

(7) Er wird nach Balifahren. 'Dia (akan) pergi ke Bali.'

\section{b. Modal}

Pada konstruksi verba kompleks modal, verba modal seperti müssen 'harus', können 'dapat', dürfen 'boleh' bergabung dengan verba bentuk infinitif untuk membentuk verba kompleks. Tidak seperti verba bantu pada konstruksi verba kompleks lainnya yang telah kehilangan makna leksikal, dalam konstruksi verba kompleks modal, verba bantu modal tetap memiliki makna leksikalnya. Contoh:

(8) Sie $m u \beta$ morgen arbeiten

'Dia besok harus bekerja.'

\section{c. Kuasi Modal}

Verba kuasi modal merupakan adaptasi dari istilah Modalähnliche Verben atau verba yang memiliki perilaku sintaktik menyerupai veba modal. Artinya verba modal kuasi berperilaku seperti verba modal, yaitu sebagai verba finit yang memiliki makna leksikal penuh dan bersama-sama dengan verba bentuk infinitif membentuk predikat kalimat. Berdasarkan tinjauan semantik verba modal kuasi dapat dibedakan menjadi tiga, yaitu (1) verba pergerakan atau arah, (2) verba inderawi, dan (c) verba kausatif.

\section{1) Verba Pergerakan}

Yang dimaksud verba pergerakan (Bewegungsverben) adalah verba yang mengandung makna adanya suatu proses atau kegiatan yang dilakukan oleh subjek untuk menuju ke suatu arah atau tempat tertentu (Eisenberg, 1994). Berikut disampaikan salah satu contoh verba pergerakan, yaitu gehen 'pergi'.

(9) Karl geht heute nachmittag einkaufen.

'Sore ini Karl pergi berbelanja.'

Pada kalimat (9) terdapat dua buah bentuk verba. Yang pertama adalah verba gehen (geht) 'pergi' yang berfungsi sebagai verba finit dan menduduki posisi kurung kiri. Verba tersebut, sebagaimana verba modal, tidak hanya memiliki makna gramatikal saja, yaitu sebagai pengungkap identitas klausa terkait dengan informasi tentang kala, persona, jumlah, dan modus; namun verba tersebut juga memiliki makna leksikal. Verba gehen (geht) bersama-sama dengan verba infinitif einkaufen 'berbelanja' membentuk predikat kalimat.

Contoh lain dari verba dengan makna pergerakan adalah kommen 'datang'. Perhatikan contoh yang dikutip dari Eisenberg (1994:371) berikut.

(10) Elisabeth kommt Karl abholen.

'Elisabeth datang menjemput Karl.'

Pada kalimat (10) di atas terdapat dua buah verba, yaitu kommt 'datang' sebagai verba pergerakan yang berperilaku seperti verba modal, dan verba infinitif abholen 'menjemput'. Kedua verba tersebut mengindikasikan bahwa kalimat (10) di atas sebetulnya terdiri dari dua klausa dengan subjek yang sama, yaitu Elisabeth. Klausa yang pertama ditandai oleh verba intransitif kommt 'datang', sedang klausa yang kedua ditandai dengan verba transitif abholen ,menjemput' dengan Karl sebagai objeknya. Kedua klausa tersebut diwujudkan dalam satu kalimat dengan konstruksi verba kompleks modal kuasi. Konstruksi infinitif di atas bersifat koheren karena kedua verba, baik finit maupun infinit, merujuk pada subjek yang sama dan terdapat hubungan dependensi di antara keduanya.

Di samping verba pergerakan yang mengindikasikan adanya suatu arah tertentu yang akan dituju, terdapat satu verba yang memiliki fitur 'statis' dengan perilaku sintaksis seperti verba modal, yaitu verba bleiben 'tinggal'. Perhatikan contoh berikut.

(11) Er bleibt imBett liegen.

Dia tinggal ditempattidur berbaring.

'Dia berbaring di tempat tidur.'

\section{2) Verba Inderawi}

Konstruksi infinitif koheren lainnya terdapat pada kalimat dengan verba inderawi. 
Yang dimaksud dengan verba inderawi adalah verba pengalam melalui alat indera (Wahrnehmungsverben), seperti sehen 'melihat', hören 'mendengar', fühlen 'merasa'. Verba inderawi termasuk pada konstruksi yang disebut Accusativus cum Infinitifo (AcI), yaitu verba yang bervalensi dengan nomina akusatif dan verba infinitif sebagai pelengkapnya. Konstruksi tersebut termasuk konstruksi infinitif yang primer sebagaimana konstruksi infinitif pada verba modal. Disebut sebagai konstruksi infinitif primer karena tidak dapat diparafrasekan dengan konstruksi lain, misalnya konstruksi klausa subordinatif (Eisenberg 1994). Berikut disampaikan contoh yang dikutip dari Eisenberg (1994:385).

(12) Helga sieht ihren Sohn rauchen.

'Helga melihat anak lelakinya merokok.'

Bila diperhatikan kalimat (12) merupakan satu kalimat dengan dua subjek yang berbeda, yaitu subjek nominatif Helga, dan subjek akusatif ihren Sohn 'anak lelakinya'. Bila diurai kalimat (12) sebenarnya terdiri dari dua klausa yaitu Helga sieht ihren Sohn 'Helga melihat anak lelakinya' dan ihren Sohn rauchen 'anak lelakinya merokok'. Verba infinitif rauchen 'merokok' juga dapat memiliki objek, misalnya eine Zigarrette 'sebatang rokok' seperti pada contoh berikut.

(13) Helga sieht ihren Sohn eine Zigarrette rauchen.

'Helga melihat anak lelakinya merokok sebatang rokok.'

\section{3) Verba Kausatif}

Yang dimaksud dengan verba kausatif, dan juga verba permisif, adalah verba finit yang memiliki fitur semantik 'menyebabkan terjadinya sesuatu'. Sementara itu, akibat dari verba kausatif berada pada verba infinitif. Sehingga dapat dikatakan bahwa "sebab” berada pada verba kausatif, yang berfungsi sebagai verba finit, dan ,akibat” berada pada verba infinitif. Konstruksi verba kompleks dengan verba kausatif pada hakekatnya merupakan kalimat majemuk yang terdiri dari dua klausa. Klausa pertama ditandai oleh verba kausatif dengan subjeknya yang berkasus nominatif, dan klausa kedua ditandai oleh verba infinitif dan subjek yang berkasus akusatif, karena subjek dari verba infinitif yang berkasus akusatif itu juga sekaligus merupakan objek dari verba kausatif. Pada contoh (14) di bawah, yang diadaptasi dari DUDEN (2005:422), pronomina ihn 'dia laki-laki (akusatif)' merupakan objek dari verba kausatif (permisif) ließ 'membiarkan' yang juga sekaligus berfungsi sebagai subjek untuk verba gehen 'pergi'.

(14) Der Lehrer ließ ihn gehen.

'Guru itu membiarkan dia (nya) pergi.'

Berikut disajikan contoh lain dari konstruksi verba kausatif dengan verba infinitif berjenis transitif yang juga diadaptasi dari DUDEN (2005:422)

(15) Die Freude darüber machte uns das andere vergessen.

'Kegembiraan (atas hal) itu membuat kami melupakan hal yang lain.'

Pada kalimat (15) pronomina uns 'kami' berkasus akusatif karena merupakan objek dari verba machte 'membuat'. Pronomina uns tersebut sekaligus juga berfungsi sebagai subjek untuk verba vergessen 'melupakan'.

\section{d. Modalitas}

Dalam bahasa Jerman terdapat sekelompok verba modalitas yang dalam kemunculannya berdampingan dengan verba bentuk ,,$z u+$ infinitif' atau infinitif dengan $z u$. Unsur infinitif (dengan $z u$ ) pada konstruksi verba kompleks modalitas bersifat koheren, artinya unsur infinitif tersebut merupakan bagian dari predikat. Dalam konstruksi tersebut verba bantu modalitas dan unsur infinitif merujuk pada subjek yang sama. Seperti halnya verba bantu yang lain, verba bantu modalitas juga mengalami pergeseran makna leksikal, sedang makna leksikal verba terdapat pada verba utama yang berbentuk , $z u$ infinitif'. Yang termasuk verba modalitas di antaranya adalah haben 'memiliki', scheinen 'nampak', pflegen 
'merawat", dan lain-lain. Sementara itu, terdapat verba modalitas yang berdiatesis pasif yaitu sein dan bleiben yang akan dibicarakan secara tersendiri pada butir (c) di bawah. Perhatikan contoh berikut:

(16) Du hast mir zu helfen.

'Kamu harus membantu saya.'

Makna leksikal verba haben (hast) adalah 'mempunyai', namun sebagai verba bantu modalitas dalam konstruksi verba kompleks modalitas pada kalimat (16) di atas haben memiliki makna modalitas 'harus' sebagaimana verba modal müssen 'harus'. Sementara itu verba utama dengan makna leksikal dari kalimat (16) di atas adalah bentuk infinitif $z u$ helfen 'membantu'. Konstruksi infinitif dengan verba bantu modalitas haben dan $z u$ infinitif merupakan „pesaing” atau alternatif lain dari konstruksi verba kompleks modal dengan verba bantu modal müssen 'harus'.

Berikut disampaikan contoh konstruksi verba kompleks modalitas yang lain, dengan verba bantu modalitas pflegen .

(17) Eva pflegt morgens Milch zu trinken.

Eva V-MODALITAS setiap pagi susu minum.

'Eva biasanya minum susu setiap pagi.'

Verba pflegen (pflegt) memiliki makna leksikal 'merawat', tetapi sebagai verba bantu modalitas pada kalimat (17) di atas maknanya berubah menjadi 'merawat kebiasaan' atau 'memiliki kebiasaan'. Sementara verba utama pada kalimat (17) adalah zu trinken yang bermakna 'minum'.

\section{c. Modalitas Pasif}

Selain konstruksi verba kompleks modalitas berdiatesis aktif seperti yang disampaikan di atas, masih terdapat konstruksi modalitas lain yang berdiatesis pasif yang disebut sebagai verba kompleks modalitas pasif (DUDEN, 2005). Konstruksi tersebut terdiri dari verba finit sein atau bleiben sebagai verba bantu modalitas (BAN-MODALITAS) dan verba infinitif dengan $z u$. Sebagaimana konstruksi pasif yang lain, pada konstruksi modalitas pasif subjeknya juga berperan pasientif yang bila ditransformasikan ke dalam kalimat aktif berfungsi sebagai objek. Konstruksi verba kompleks modalitas pasif merupakan alternatif lain dari konstruksi verba kompleks kombinasi antara verba kompleks modal dengan pasif (DUDEN, 2005). Perhatikan contoh kalimat (18) di bawah ini yang dikutip dari DUDEN (2005:556).

(18) Der Schmerz ist kaum zu ertragen.

Rasa nyeri itu BAN-MODALITAS hampir tidak ditahan.

'Rasa nyeri itu hampir tidak dapat ditahan.'

Konstruksi verba kompleks modalitas pasif memiliki makna lebih kurang 'untuk di........' atau 'dapat di.........'. Kalimat (18) yang berkonstruksikan verba kompleks modalitas pasif itu dapat juga dinyatakan dengan konstruksi verba kompleks kombinasi antara verba kompleks modal dan pasif seperti pada kalimat (19) di bawah ini.

(19) Der Schmerz kann kaum ertragen werden.

'Rasa nyeri itu hampir tidak dapat ditahan.'

Meskipun kalimat (18) dan kalimat (19) dinyatakan dengan konstruksi verbal yang berbeda, kedua kalimat tersebut memiliki makna yang sama. Hal itu menunjukkan bahwa konstruksi verba kompleks modalitas pasif merupakan alternatif bagi konstruksi verba kompleks kombinasi antara verba kompleks modal dan pasif.

\section{Konstruksi Infinitif Inkoheren}

Seperti telah disebutkan di atas, bahwa konstruksi infinitif inkoheren memiliki nilai sintaksis atau nilai kalimat (satzwertig). Dalam kaitannya dengan nilai kalimat itu, DUDEN (2005) lebih lanjut membedakan konstruksi infinitif inkoheren menjadi dua, yaitu konstruksi yang bernilai (induk) kalimat (hauptsatzawertig) dan yang bernilai anak kalimat (nebensatzwertig). Konstruksi infinitif inkoheren yang bernilai induk kalimat (hauptsatzwertig) banyak dijumpai pada "kalimat" yang berisi petunjuk, pemberitahuan, 
peringatan, dan larangan, contoh:

(20) Bitte abends die Tür zuschlieâen. 'Malam hari pintu harap dikunci'

(21) Bitte den Wagen nicht berühren! 'Mohon jangan menyentuh kereta/ mobil!'

(22) In der Nacht ohne Begleitung nicht ausgehen!

'Jangan (dilarang) pergi pada malam hari tanpa pengawalan'

Contoh-contoh (20 s/d 22) di atas adalah konstruksi infinitif inkoheren yang bernilai kalimat (satzwertig). Pada konstruksi infinitif koheren bentuk infinitif yang digunakan tanpa $z u$. Meskipun secara gramatik formal contoh-contoh di atas bukan merupakan kalimat, karena tidak terdapat subjek dan predikat, dan lebih mendekati bentuk frasa, namun secara semantik dan pragmatik bernilai kalimat. Dalam contoh-contoh di atas, secara struktur batin (deep stucture) yang menjadi subjek adalah pembaca yang menjadi adresat dari tulisan-tulisan atau "kalimat" itu. Faktor lain yang memperkuat bahwa contoh-contoh di atas bernilai kalimat adalah adanya pemarkah kasus pada nomina yang berfungsi sebagai objek. Dalam bahasa Jerman nomina objek berkasus akusatif. Pada contoh (20) dan (21) bentuk infinitif zuschlieâen 'mengunci' dan berühren 'menyentuh' merupakan verba transitif yang masing-masing menuntut nomina objek die Tür 'pintu' dan den Wagen 'kereta/ mobil' yang berkasus akusatif. Pemarkah kasus akusatif dari kedua nomina objek tersebut tersematkan pada artikel nomina, yaitu die (Tür) dan den (Wagen).

"Kalimat" (20) di atas merupakan contoh pentunjuk atau pemberitahuan yang biasa ditemukan pada pintu masuk utama dalam sebuah bangunan yang di dalamnya terdapat sejumlah apartemen (Wohnungen). Pemberitahuan atau peringatan itu berasal dari pengelola gedung apartemen (Hausmeister) kepada para penghuni apartemen. Contoh (21) merupakan larangan yang bisa dijumpai pada museum atau pameran kereta atau mobil, kata Wagen dalam bahasa Jerman dapat berarti 'kereta' atau 'mobil'. Contoh tersebut memperingatkan pengunjung museum atau pameran kereta/ mobil untuk tidak menyentuhnya; mereka hanya diijinkan untuk melihatnya saja. Sementara contoh (22) merupakan peringatan untuk keselamatan.

Konstruksi infinitif inkoheren yang bernilai anak kalimat (nebensatzwertig) merupakan penjelas atau pemerluas dari unsurunsur yang ada pada induk kalimat. Oleh sebab itu konstruksi infinitif tersebut akan merujuk pada unsur-unsur dalam induk kalimat yang diperluasnya. Berikut ini disampaikan uraian tentang unsur-unsur pada induk kalimat yang dirujuk dan diperluas oleh konstruksi infinitif.

\section{a. Konstruksi infinitif yang merujuk pada subjek}

Salah satu konstutuen yang sering dirujuk oleh konstruksi infinitf inkoheren adalah subjek. Perhatikan contoh (23) berikut.

(23) Die Sekretärin versprach den Chef, den Bericht sofort zu erledigen.

'Sekretaris berjanji pada pimpinan untuk segera menyelesaikan laporan.'

Pada contoh (23) di atas konstruksi infinitif den Bericht sofort zu erledigen 'untuk segera menyelesaikan laporan' merujuk pada fungsi subjek die Sekretärin 'sekretaris', oleh sebab itu subjek pada (induk) kalimat sekaligus juga menjadi subjek dari konstruksi infinitif. Dengan demikian subjek die Sekretärin 'sekretaris' pada kalimat di atas melakukan dua tindakan seperti yang dinyatakan pada verba finit versprach 'berjanji' dan verba infinitif $z u$ erledigen 'menyelesaikan'. Jika kalimat di atas diparafrasekan menjadi kalimat majemuk bertingkat akan menghasilkan kalimat (23a) berikut.

(23a) Die Sekretärin versprach den Chef, dass sie den Bericht sofort erledigen will.

'Sekretaris berjanji pada pimpinan, bahwa dia akan segera menyelesaikan laporan.'

Kalimat (23a) di atas adalah kalimat majemuk bertingkat yang lengkap unsurunsurnya. Perubahan dari konstruksi infinitif 
pada contoh (23) menjadi konstruksi anak kalimat pada contoh (23a) ditandai oleh beberapa hal, pertama, munculnya subjungsi dass sebagai penghubung antara anak kalimat dengan induk kalimat; kedua, kemunculan subjek dalam bentuk pronomina persona ketiga tunggal feminin sie 'dia (perempuan)' yang merupakan pengganti subjek pada induk kalimat die Sekretärin 'sekretaris'; dan ketiga, perubahan verba zu erledigen dalam konstruksi infinitif menjadi verba kompleks erledigen will pada anak kalimat. Verba erledigen bersamasama dengan verba finit (modal) will 'akan' membentuk verba kompleks sebagai predikat anak kalimat. Dengan perubahan itu maka verba infinitif erledigen pada kalimat (23a) bersifat koheren.

\section{b. Konstruksi infinitif yang merujuk pada objek}

Contoh pada kalimat (24) di bawah pada prinsipnya sama dengan contoh (23) di atas. Perbedaannya adalah pada contoh (24) yang dirujuk oleh konstruksi infinitif adalah fungsi objek. Perhatikan contoh (24) berikut.

(24) Der Chef bittet die Sekretärin, den Bericht sofort zu erledigen.

'Pimpinan minta pada sekretaris untuk segera menyelesaikan laporan.'

Pada kalimat (24) di atas, objek induk kalimat die Sekretärin 'sekretaris' adalah juga merupakan subjek pada konstruksi infinitif. Apabila kalimat di atas bentuknya diubah menjadi kalimat majemuk bertingkat yang lengkap, maka akan menghasilkan kalimat (24a) berikut.

(24a) Der Chef bittet die Sekretärin, dass sie den Bericht sofort erledigen soll.

'Pimpinan minta pada sekretaris, agar dia segera menyelesaikan laporan.'

Konstruksi (frasa) infinitif pada contoh (24) telah diubah menjadi konstruksi anak kalimat pada contoh (24a) di atas. Perubahan konstruksi dari infinitif menjadi anak kalimat ditandai oleh oleh beberapa hal, yaitu pertama, adanya subjungsi dass, yang menghubungkan anak kalimat dengan induk kalimat; kedua, kemunculan pronomina sie 'dia', yang merujuk pada nomina die Sekretärin, sebagai subjek anak kalimat; dan ketiga perubahan bentuk infinitif zu erledigen menjadi verba kompleks erledigen soll. Bentuk infinitif erledigen pada anak kalimat (24a) tidak bersifat inkoheren, melainkan koheren karena bentuk itu tidak menjalankan fungsi predikat secara mandiri melainkan bersama-sama dengan verba finit modal soll. Kehadiran verba modal soll (sollen) 'agar' pada contoh (24a) di atas adalah sebagai penanda kalimat imperatif atau permintaan tak langsung yang berasal dari orang ketiga.

\section{c. Konstruksi infinitif sebagai subjek}

Konstruksi infinitif juga dapat berfungsi sebagai subjek kalimat. Perhatikan contoh berikut.

(25) Die ganze Nacht das Fussballspiel im Fernsehen zu sehen macht müde.

'Semalaman menonton sepak bola di televisi membuat ngantuk.'

Pada kalimat di atas subjeknya berupa konstruksi (frasa) infinitif die ganze Nacht das Fussballspiel im Fernsehen zu sehen 'semalaman menonton sepak bola di televisi'. Yang menjadi inti atau poros dari konstruksi tesebut adalah verba infinitif $z u$ sehen 'melihat', sedang nomina Fussballspiel '(permainan/ pertandingan) sepak bola' adalah objeknya, dan frasa nominal die ganze Nacht 'semalaman' berfungsi sebagai adverbia temporal. Konstruksi infinitif tidak memiliki subjek eksplisit yang mandiri, karena subjeknya biasanya merujuk pada unsur lain pada kalimat di atasnya (induk). Akan tetapi pada kalimat (24) di atas tidak ada unsur yang dapat dirujuk sebagai subjek oleh konstruksi infinitif; dalam hal demikian, sebagai subjek 'imajiner' yang dapat digunakan adalah pronomina indefinit man 'orang/ kita' (DUDEN, 2005). Untuk itu, jika konstruksi infinitif pada contoh (25) diparafrasekan menjadi anak kalimat, maka bentuknya seperti pada contoh (25a) berikut.

(25a) Dass man die ganze Nacht das Fussballspiel im Fernsehen sieht, macht müde. 
'Bahwa orang/ kita semalaman menonton sepak bola di televisi, membuat ngantuk.'

Perubahan dari konstruksi infinitif menjadi konstruksi anak kalimat seperti pada contoh (25a) di atas ditandai oleh munculnya subjek man 'orang/ kita' dan perubahan verba dari bentuk infinitif $z u$ sehen 'melihat' pada konstruksi infinitif menjadi verba finit sieht 'melihat' pada konstruksi anak kalimat.

\section{d. Konstruksi infinitif yang merujuk pada korelat.}

Konstruksi infinitif juga ada yang merujuk pada korelat. Bentuk korelat dalam bahasa Jerman adalah pronomina ketiga tunggal yang bergenus neutrum es. Dalam kalimat, korelat es dapat menduduki posisi subjek maupun objek. Korelat es akan dirujuk secara anaforis oleh suatu konstruksi sintaksis yang menjadi penjelasnya atau perluasannya. Salah satu konstruksi sintaksis yang dapat berfungsi sebagai penjelas korelat es tersebut adalah konstruksi infinitif. Perhatikan contoh (26) berikut.

(26) Es freut mich sehr, dich wiederzusehen.

'(Ini) sangat menggembirakanku, (untuk) berjumpa lagi denganmu.'

Pada contoh (26) di atas korelat es menduduki posisi subjek dan dirujuk secara anaforis oleh konstruksi infinitif dich wiederzusehen 'berjumpa lagi denganmu'. Tanpa kehadiran konstruksi infinitif maka kalimat (26) di atas menjadi tidak bermakna, karena secara substansial yang menjadi subjek dari kalimat (26) di atas adalah konstruksi infinitif dich wiederzusehen 'berjumpa lagi denganmu', sementara bentuk es hanyalah subjek formal yang sekaligus berperan sebagai korelat.

Korelat pada kalimat (26) di atas juga dapat dihilangkan. Jika demikian, maka konstruksi infinitif dich wiederzusehen 'berjumpa lagi denganmu' berfungsi sebagai subjek dan menempati posisi awal kalimat menggantikan es, sehingga kalimatnya menjadi seperti pada contoh (26a) berikut. (26a) Dich wiederzusehen freut mich sehr.

'Berjumpa lagi denganmu sangat menggembirakanku.'

Konstruksi kalimat (26a) sama dengan konstruksi kalimat (25) di atas, yaitu samasama bersubjek konstruksi infinitif. Penggunaan konstruksi infinitif dengan korelat seperti pada contoh (26) semata-mata hanyalah untuk memberikan efek stilistik.

Di samping sebagai subjek, seperti pada contoh (26) di atas, koelat es dapat pula berfungsi sebagai objek. Perhatikan contoh (27) berikut.

(27) Stefan mag es gern, in der Freizeit im Garten zu arbeiten.

'Stefan menyukaI itu(korelat), bekerja di kebun pada waktu senggang.'

Pada contoh (27) konstruksi infinitif in der Freizeit im Garten zu arbeiten '(untuk) bekerja di kebun pada waktu senggang' secara anaforis merujuk pada korelat es yang berfungsi sebagai objek dari verba mag (mögen) 'menyukai'. Tanpa konstruksi infinitif tersebut kalimat menjadi tidak bermakna, karena secara substansial yang menjadi objek kalimat adalah konstruksi infinitif. Bentuk es pada contoh (27) di atas "hanyalah" sebagai objek formal yang sekaligus berfungsi sebagai korelat.

Kalimat (27) juga dapat diubah menjadi kalimat tanpa korelat es. Akan tetapi perubahan itu mensyaratkan adanya topikalisasi objek, yang dalam hal ini adalah konstruksi infinitif in der Freizeit im Garten zu arbeiten '(untuk) bekerja di kebun pada waktu senggang'. Dengan adanya morfologi infleksional dalam bahasa Jerman, yang berupa pemarkah deklinasi dan konjugasi, topikalisasi objek dapat dilakukan dengan mudah tanpa mengubah struktur maupun diatesis kalimat dari aktif menjadi pasif. Perubahan kalimat (27) menjadi tanpa korelat akan menghasilkan kalimat (27a) berikut.

(27a) In der Freizeit im Garten zu arbeiten mag Stefan gern.

'Bekerja di kebun pada waktu senggang, Stefan menyukainya.' 
Pada kalimat (27a) di atas, objek yang berupa konstruksi infinitif dan telah mengalami proses topikalisasi, letaknya di depan kalimat. Perubahan letak objek tersebut tidak mengubah makna kalimat. Hal ini diebabkan adanya konjugasi verba dan pemarkah kasus nomina sesuai dengan fungsi sintaksisnya.

\section{e. Konstruksi infinitif yang diawali oleh subjungsi}

Terdapat sejumlah konstruksi infinitif yang diwali oleh subjungsi seperti um 'untuk/ agar', ohne 'tanpa', anstatt 'sebagai ganti', dan lain sebagainya. Konstruksi yang demikian disebut juga sebagai kalimat infinitif atau Infinitifsatz. Konstruksi infinitif yang diawali oleh subjungsi juga termasuk konstruksi infinitif yang koheren. Konstruksi tersebut merujuk pada subjek. Perhatikan contohcontoh berikut.

(28) Maria studiert Pädagogik, um Lehrerin zu werden.

'Maria kuliah ilmu kependidikan agar menjadi guru.'

(29) Anna nimmt die Pille ein, ohne Gebrauchtsanweisung zu beachten.

'Anna minum pil tanpa memperhatikan aturan penggunaannya.'

(30) Anstatt die Hausaufgabe zu machen, sieht Peter fern.

Bukannya (sebagai gantinya) mengerjakan pekerjaan rumah, Peter (malah) menonton televisi.

Tidak jarang pula dijumpai konstruksi infinitif yang merujuk pada konstituen yang ada dalam kalimat pasif. Berikut ini adalah contohnya.

(31) Um den Strom zu sparen, wurde die Klimaanlage nur am Tag eingestellt.

'Untuk menghemat listrik, AC hanya dinyalakan pada siang hari.'

\section{PENUTUP}

\section{Kesimpulan}

Dari uraian di atas dapat disampaikan beberapa kesimpulan berikut. a. Dalam bahasa Jerman verba infinitif bergabung bersama verba infinit membentuk verba kompleks untuk menjalankan fungsi predikat kalimat. Konstruksi sintaksis yang mengandung unsur infinitif itu disebut juga sebagai konstruksi infinitif.

b. Berdasarkan hubungan unsur infinitif dengan verba finit, konstruksi infinitif dibedakan menjadi dua, yaitu konstruksi infinitif yang koheren dan yang inkoheren.

c. Pada konstruksi infinitif koheren unsur infinitif merupakan bagian dari verba kompleks yang menjalankan fungsi predikat kalimat, sehingga tidak bernilai kalimat (nicht satzwertig), sementara pada konstruksi infinitif inkoheren unsur infinitif merupakan verba yang menjalankan fungsi predikasinya secara mandiri, sehingga bernilai sintaksis atau bernilai kalimat (satzwertig).

\section{Implikasi}

Berdasarkan kesimpulan di atas dapat dikemukakan implikasi dalam pengajaran bahasa Jerman bagi pembelajar Indonesia sebagai berikut.

a. Dalam tataran frasa, khususnya pada verba kompleks bahasa Jerman (termasuk konstruksi infinitif), terdapat peristiwa morfosintaksis yang nampak pada perbedaan bentuk morfologis verba finit dan infinitif. Perbedaan bentuk ini juga diikuti oleh perbedaan fungsi dan makna dari kedua verba tersebut. Ditinjau dari distribusi unsur verba kompleks (verba finit dan infinitif) dalam induk kalimat bahasa Jerman, konstruksi infinitif merupakan konstruksi verbal diskontinu, dengan verba finit menempati rangka kalimat kiri dan verba infinitif menempati rngka kalimat kanan. Sementara pada konstruksi anak kalimat semua unsur verba kompleks berada pada rangka kalimat kanan.

b. Konstruksi infinitif koheren merupakan konstruksi primer, artinya tidak dapat diparafrasekan ke dalam bentuk konstruksi 
lain. Sementara konstruksi infinitif inkoheren bukan merupakan konstruksi primer, sehingga merupakan alternatif dari konstruksi sintaksis yang lain dan fungsinya lebih ditikberatkan pada efek stilistik.

\section{DAFTAR PUSTAKA}

DUDEN. 2005. Die Grammatik. Völlig neu bearb. 7. Auflage. Mannheim, Leipzig, Wien, Zürich: Dudenverlag

Eisenberg, Peter. 1994. Grundriss der deutschen Grammatik. Dritte Auflage. Stuttgart, Weimar: Verlag J.B. Metzler.

Glück, Helmut. (Hg.). 1993. Metzler-Lexikon Sprache. Stuttgart, Weimar: Verlag J.B. Metzler. 